\title{
Facetas da literacia: processos da construção do sujeito letrado ${ }^{1}$
}

The various stances of literacy: processes for the production of the literate subject

Maria de Lourdes Dionísio²

À professora Magda Soares

Ao professor João Wanderley Geraldi

\section{Resumo}

Partindo-se de um entendimento de literacia como prática socialmente situada que implica quer a manipulação da palavra escrita, quer comportamentos, valores, crenças, e saberes sobre o que pode ser dito e feito, como e com que "acessórios", num domínio de prática particular, discutem-se, neste texto, algumas estratégias que, no âmbito da leitura realizada na escola, têm por função assegurar uma dada configuração da literacia e do sujeito que aí é reconhecido como letrado. Para além das estratégias discursivas que, na aula de língua portuguesa e em manuais escolares, conformam as características do leitor legítimo, discutem-se as representações de leitura e de leitor veiculadas pelos textos antologiados num corpus de manuais escolares. Entre as principais conclusões, destaca-se a visão restrita das funções sociais da leitura bem assim como do papel do leitor, construído que é numa prática de aceitação daquilo que uma voz com autoridade define como a prática de leitura que conta naquele contexto.

Palavras-chave: Literacia; Discurso da Aula; Manuais Escolares

\section{Abstract}

This text explores the notion of literacy as a socially situated practice which is more than skills and processes of reading and writing, therefore including behaviours, values, beliefs and knowledges about what can be done with words and how, with what kind of tools, in a particular domain of practice. The analysis is conducted upon some pedagogical devices, such as the discursive strategies of the classroom interaction as well as some of school textbooks, that ensure a particular literacy and a particular literate person, as well as upon representations of reading and of the reader conveyed by the texts of a corpus of language textbooks. Among the main conclusions, it is worth to note the restricted version of literacy and of the role of the reader, whose constructed position is that of acceptance of a voice with authority defines for them as good reading practice.

Keywords: Literacy; Classroom Discourse; School Textbooks

1 Este texto, produzido no âmbito de uma licença sabática financiada pela Fundação para a Ciência e Tecnologia (FCT-PT) é uma versão revista e alargada do texto apresentado na $29^{a}$ Reunião Anual da ANPED, em 17 de outubro de 2006. Agradeço às professoras Cancionila Janzkovski, da UFMT, e Aracy Martins, da UFMG, as condições criadas para a produção deste texto; a Rui Vieira de Castro, da UM-PT, os contributos para a sua versão final.

2 Universidade do Minho, Portugal. A autora desenvolve actividades de ensino e investigação no âmbito da formação de professores de Português e das práticas de literacia de jovens e adultos. O discurso da aula e os manuais escolares têm constituído objectos privilegiados da sua pesquisa.mldionisio@iep.uminho.pt. 


\section{A(s) Literacia(s): PARA alÉm do código escrito}

As práticas de literacia ${ }^{3}$ na escola e as práticas de ensino da literacia estruturam-se sobre um conjunto vasto de processos, activados por um largo número de dispositivos que produzem, numa determinada posição, os sujeitos que aí interagem "sobre textos, com textos e à volta de textos" (LUKE, 2001), com vista à aquisição e construção dos saberes escolares. Ao mesmo tempo, por tais processos e dispositivos produz-se e reproduzse uma prática sociocultural que podemos reconhecer como própria deste "domínio de prática": 4 a escola.

É o reconhecimento da acção de tais processos e dispositivos que cria a possibilidade de, ao falarmos, hoje, de literacia, o fazermos já no plural: literacias ou mesmo multiliteracias, literacias múltiplas, etc.; marcase, por essa forma, a existência da especificidade das práticas que envolvem o escrito em múltiplos domínios da vida como, por exemplo, a família, os lugares de trabalho, a associação, etc. Desde logo porque, em cada um desses domínios, são visíveis modos "preferidos" de fazer sentidos com os textos, modos particulares de os usar e, mesmo, de sobre eles falar (cf. CASTRO; DIONÍSIO, 2003). Mas também porque, nessas práticas, em associação com o uso de linguagem apropriada e, como tal, em associação, também, com modos próprios de falar e ouvir e não só de ler e escrever, estão intrinsecamente envolvidos modos próprios de usar determinados objectos, símbolos, ferramentas, tecnologias, de valorizar, acreditar, sentir estruturas de relações de poder sustentadoras das práticas socioculturais em jogo. (GEE, 1999)

Nesse quadro, ser letrado num determinado domínio de prática é possuir e poder exibir um bilhete de identidade em que consta um número alargado de traços pessoais que estão para além dos estritamente relativos às habilidades e processos de manipulação da palavra escrita, para incluir os comportamentos, os valores, as crenças, os saberes, por vezes tácitos, sobre o que pode ser dito e feito, como e com que "acessórios" naquele

Apesar da heterogeneidade do uso, em Portugal, do conceito de literacia, podemos dizer que, aqui, neste texto, o conceito é equivalente ao de letramento em uso no Brasil.

4 Um "domínio de prática" pode ser visto como um "espaço", uma "esfera de acção" ou mundo em que a literacia tem uma função social (cf. STREET, 1984; BARTON; HAMILTON, 1998; BARTON; HAMILTON; IVANIC, 2000). 
domínio particular. Esses traços adquirem-se e aprendem-se por processos de socialização vários e segundo as normas e ideologias das instituições ou grupos que configuram um dado domínio de prática, no qual os sujeitos actuam. Nesse sentido, podemos falar da literacia como uma prática socialmente situada.

Nessa linha de ideias, ter sucesso na escola, isto é, ser aí reconhecido e aceite como membro de direito dessa comunidade que, mais do que qualquer outra, é um domínio de literacia, é função das condições de cada um, e das condições para cada um construídas, exibir aqueles traços, adoptando os procedimentos verbais, os comportamentos, os valores e as crenças que aí são definidos como legítimos, usando de forma "adequada" à instituição as ferramentas e tecnologias aí estabelecidas como válidas. Em muito, é ter condições para se (in)vestir ${ }^{5}$ das palavras, acções e modos de relação com os outros e com os objectos que valem ali, naquele contexto. Nas palavras de um professor, é aceite

aquele que aceita a regra escolar, que as cumpre, que as pratica e que dentro dessa prática da regra escolar faz um progresso substantivo e sustentado nos vários saberes que constituem o seu currículo escolar [...] Portanto, o bom aluno é aquele que não só aceitou e pratica o método escolar, como a partir dessa prática, dessa aceitação, revela uma aquisição progressiva de conhecimentos e depois os sabe usar... O mau aluno é aquele que não só vai mostrando uma grande resistência à escolarização, ao cumprimento das regras, à aceitação da disciplina, a trazer os materiais para a escola, a cumprir as tarefas... (PASSOS, 2006)

A produção daquelas possibilidades estrutura-se sobre e a partir de práticas discursivas que, no que diz respeito à leitura e à escrita (à matéria da literacia, portanto), são expressão de determinadas "formações discursivas", cujos filtros, segundo Haroche, Henry e Pêcheux (1971), determinam o que pode ser dito e feito, e como e em que condições pode ser dito e feito numa dada conjuntura. São, assim, as práticas discursivas de cada domínio que definem as condições do exercício da literacia,

5 Vale dizer que este (in)vestimento, tal qual J. Wanderley Geraldi o conceptualizou em discussão científica na $29^{a}$ Reunião Anual da ANPED, pode ser muitas vezes um (des)vestimento da "subjectividade, das posições ideológicas e das vontades políticas" (GERALDI, 2006, p. 16) de cada um e do grupo a que pertence.

6 Os destaques são da minha responsabilidade. 
nomeadamente, quem é e qual o papel do letrado. Por tudo isso, falar de uma literacia é sempre contar uma narrativa histórica, institucional e social sobre o que "vale", num dado lugar, como prática de leitura e de escrita.

\section{Da sala de aula aos manuais escolares}

Na escola, são vários os lugares onde é possível recuperar uma tal narrativa e verificar como a literacia na e da escola, ao contrário do que certas perspectivas fazem crer e, ainda mais, ao contrário das avaliações padronizadas e assentes nos processos linguístico e cognitivos envolvidos no trabalho com o código escrito (como as avaliações globais cada vez mais reguladoras das locais), está para além dos "skills" e "processos", não podendo, assim, ser descrita como "um estado cognitivo ou um conjunto universal de capacidades e processos que os sujeitos devem aprender", 7 como recordam Barbara Comber e Phil Cormack (1997, p. 22). ${ }^{8}$

Estruturando-se toda a acção escolar em práticas discursivas, estas produzem as condições de ser ou não letrado, ao mesmo tempo que produzem e reproduzem o que é a literacia escolar.

Nas práticas interaccionais que têm lugar na sala de aula, especificamente da aula de língua (que tomaremos aqui como objecto central deste texto), produzem-se, juntamente com os saberes declarativos e processuais sobre os textos, sentidos e saberes que estão para além dos estritamente textuais, conformando-se, assim, uma "competência letrada" que acaba por ser uma questão de

"exibição" cultural (o que é visto como "bom trabalho" ou desempenho bem-sucedido numa sala de aula ou centro educativo são modos culturalmente preferidos de falar, ouvir e comportarse). (COMBER; CORMACK, 1997, p. 22)

Tomando como exemplo o momento da leitura dos textos que se realiza em sala de aula, verifica-se como, por meio de estratégias discursivas várias, se produz quem pode e quem não pode ser leitor e quais as condições necessárias para aí ser bem-sucedido. Tais sentidos, que definem a "competência letrada" na escola, são, por exemplo, relativos a condutas

7 Neste texto, as traduções das citações são da minha responsabilidade.

8 Sobre o facto de a literacia não "estar localizada na cabeça das pessoas" ou não ser "um processo igual para todos em todas as situações”, veja-se, por exemplo, Castanheira et al., 2001. 
e atitudes, nomeadamente quanto a modos de falar, a modos de estar, a modos, até, de manipular os suportes textuais:

P.: [...] que caminhadas são essas Cristina?

Cris.: da vida

P.: da vida sim mas tens de falar alto

Pedro: é tímida s’tôra

P.: não estou a falar contigo, espera /a tua vez/

Als.: / risos/

P.: Calma Fernando então diz lá Lopes Lopes põe-te direito achas que consegues escrever alguma coisa assim nessa posição?

P.: Ruben põe o livro em cima da mesa [o aluno lê com o livro ao alto] estás a ver os teus colegas?

Mas esta competência é também constituída por sentidos e saberes sobre como se deve pensar e a que ritmo ou mesmo sobre o sentido social da prática de literacia que aí se leva a cabo:

P.: que estás a fazer agora?

Cátia: Já li s’tôra

P.: Já leste?! Então lê outra vez

Raúl: era um filme não era um filme?

P.: Ainda não chegámos aí

P.: O senhor José João já escreveu a frase? Faça o favor, já que não a disse, pelo menos escreva. ${ }^{9}$

Mas, no estabelecimento destas e de outras normas relativas ao uso dos textos na escola, actuam outros dispositivos, designadamente os manuais escolares. Aqui, tanto os textos que integram as suas antologias, como as actividades sobre esses textos, geralmente na forma de questionários, guiões de leitura, exercícios e sugestões de escrita, são meios privilegiados para produzir o que na escola vale e deve valer como literacia e sujeito letrado.

No âmbito das actividades de leitura a propósito dos textos, a que circunscreveremos, a partir de agora, a literacia escolar, são várias as

9 Todos os exemplos transcritos, à excepção do último, disponibilizado por Aracy Martins a partir de um corpus de aulas recolhido em Portugal, em 2005, fazem parte do corpus recolhido em 1989, no âmbito de um estudo sobre a interacção verbal na aula de Português (cf. DIONÍSIO DE SOUSA, 1993). 
estratégias que participam nessa produção. De entre elas, para além das próprias perguntas, assumem um papel relevante os enunciados enquadradores ${ }^{10}$ que, exibindo graus variáveis de controlo sobre as relações entre os sujeitos e entre estes e os textos (cf. BERNSTEIN, 1990; DOMINGOS et al., 1986; CASTRO, 1995), criam sentidos sobre, entre outras dimensões:

i) os textos válidos (e não tão válidos) naquela comunidade e as suas características, os quais, por isso, devem ser assim valorizados (e referidos) quer por professores quer pelos alunos:

Aproveita este belo texto.

Aprecia estas duas belíssimas descrições.

Este texto é tão engraçado que merece ser lido.

Bonita descrição esta a do castelinho.

A beleza da construção deste texto...

O texto apresenta-te uma bela mensagem.

Texto com indiscutível qualidade artística.

Como deves ter reparado, a linguagem de Miguel Torga é muito sugestiva e de grande valor expressivo.

Repara que José Saramago escreve de forma original $;{ }^{11}$

ii) os comportamentos de leitura adequados e que devem caracterizar os membros daquele grupo nos eventos de literacia que levam a cabo, pelo menos ali:

Se leres este texto com atenção, dar-te-ás conta da existência de palavras e expressões características de Cabo Verde.

Se lermos cuidadosamente o texto verificamos que ...

Para melhor compreenderes o texto, resolve este exercício $[\ldots]$

10 Constituídos por enunciados produzidos pelos autores dos manuais, estes actos a que chamamos "enquadradores", e que acompanham ou mesmo integram os questionários sobre os textos, estabelecem as relações entre os sujeitos do discurso e/ou entre estes e os textos, projectando e conformando os conhecimentos, processos, crenças e valores de natureza variada que é legítimo associar aos textos (cf. DIONíSIO, 2000).

11 Todos esses exemplos, como os que a partir de agora se apresentarão, fazem parte do corpus de manuais escolares analisados em Dionísio (2000). 
Para melhor compreenderes o sentido deste texto, responde à seguinte questão;

iii) e, mesmo, os sentimentos e emoções que devem andar associados e ser manifestados neste domínio da literacia:

Lendo, gozaste o prazer de aventura!

Lê o seguinte texto e entusiasma-te!

Lê o seguinte texto com entusiasmo.

Sobre os exemplos citados em iii), note-se a força da relação entre os sujeitos (alunos e autor do manual), de tal ordem que um deles assume ter poder para controlar as emoções pessoais do outro.

Por meio de dispositivos mais simples, como por exemplo o recorte e a citação do texto a anteceder as perguntas, ou por meio de enquadradores como: "Relê o primeiro parágrafo", "Atenta nos dois primeiros versos", (cuja função não é outra que a de regulação - tal como na sala de aula de ritmos de leitura e de aprendizagem, nesse sentido, equivalendo a ordens como: Estamos aqui/ deves estar aqui. É aqui e só aqui que tens de ler), marcase o que se pode e não pode ler e interpretar, o que é e não é digno de atenção, ao mesmo tempo que se participa na construção da autoridade com poder para tudo isso definir.

Tais estratégias, aqui sumariamente exemplificadas, configuram muito perigosamente, por um lado, formas de reforço de determinadas vozes e, por outro lado, de imposição e manutenção do silêncio de que nos fala Geraldi (2006, p. 14), a propósito das exigências à escola para que "exerça sua função de refrear a língua". Nesse caso, ensina-se tanto "o bem falar" (idem), também sobre os textos, como o bem pensar, o bem sentir e o bem comportar-se.

\section{REPRESENTAÇões de Literacia nos MANuAis escolares}

Mas não são apenas as actividades, por meio das suas perguntas e, muito especialmente, por meio de dispositivos como os enquadradores, que, nos manuais escolares, desempenham essa função. Também os textos que integram a sua secção antológica consubstanciam uma forma de definição, não só dos saberes declarativos e processuais, neste caso sobre a leitura, mas também de valores, princípios, atitudes e orientações para condutas individuais e sociais no âmbito de práticas de literacia. Por meio 
de representações de mundos de literacia veiculadas pelos textos, inseremse professores e alunos nas práticas de literacia dominantes, as quais, como bom exemplo, se espera venham a provocar os efeitos que sempre norteiam a selecção dos textos para um manual.

\section{A leitura vai à escola}

Os textos dos manuais escolares, enquanto visões e versões de mundo, acolhem experiências sobre a vida, representações simbólicas susceptíveis de serem transmitidas e adquiridas pelas gerações enquanto parte da sua formação social. Pelos textos "apresentam-se aos alunos normas relativas às relações humanas e ao comportamento individual, instituições e valores sociais, em suma, o que numa sociedade é considerado importante ou não" (DENDRINOS, 1997, p. 233). Nesse sentido, os textos são "construções ideológicas" que funcionam como um dispositivo que participa, entre os outros até agora vistos, no processo mais vasto de socialização dos sujeitos e da (conformação) das comunidades em que eles se organizam. A par de outras construções, também os textos participam na formação de uma identidade do sujeito, entendida esta na sua dimensão de produto da acção de uma dada prática sociocultural que, pela linguagem, pelo discurso, modela os indivíduos.

Nesse sentido, é possível pensar que a literacia, enquanto prática e produto valorizados socialmente e na qual se quer envolver os alunos, possa constituir um elemento dessas visões e versões de mundo. É ainda possível pensar que, pelo discurso produzido acerca dos textos, aquelas visões do mundo tenderão a ser mais ou menos naturalizadas, isto é, tenderão a ser apresentadas ou como interpretações subjectivas ou como realidade.

Com esse entendimento, analisaram-se dezoito manuais escolares do $7^{\circ}$ ano de escolaridade, ${ }^{12}$ editados em 1993, em Portugal, no âmbito da implementação de um novo programa da disciplina de Língua Portuguesa. Com vista à caracterização das representações de literacia, especificamente, no domínio da leitura, presentes nesses manuais escolares, procedeu-se à identificação da presença e relevância do tópico leitura em todos os textos das antologias (narrativos e poéticos), bem assim como no discurso à

12 Aos manuais escolares analisados, constantes da bibliografia passiva, foi atribuída uma letra com a qual, a partir de agora, serão identificados. 
volta desses textos. Tal identificação consistiu na sinalização da referência à leitura ou similar, em situações do tipo das destacadas nos seguintes enunciados, transcritos dos textos, e de enquadradores discursivos, incluídos nesses manuais:

No Domingo, ouvi os meus discos e li (Man. M, p. 84);

Folhear um livro é espreitar para dentro de uma caixinha sem chave (Man. K, p. 68);

Viemos em excursão a Lisboa porque ganhámos um concurso sobre os descobrimentos. Fartámo-nos de estudar e de investigar (Man. N, p. 23);

Voltei então a me empolgar pelas aventuras de Tarzan ou pelas desventuras de Robinson Crusoé (Man. N, p. 77);

Os homens ouvem as telefonias, lêem os jornais (Man. F, p. 128);

Procura ler alguns destes livros (Man. M, p. 126).

Com esse procedimento, encontraram-se 160 referências distribuídas pelos 18 manuais (101 em textos narrativos; 38 em textos poéticos; 21 em enquadradores). Embora a presença seja muito baixa por comparação à totalidade de textos desses manuais - 2506 -, deve dizer-se que todos incluem de alguma forma tal referência.

Mesmo assim, estamos perante uma subalternização da leitura enquanto assunto do manual e, potencialmente, da aula. Essa posição torna-se particularmente evidente quando confrontamos esse número com os relativos a textos sobre o desporto ou sobre ecologia/ambiente e protecção da natureza: 32 e 40, respectivamente. Em alguns manuais, para o que muito contribui a sua organização temática, encontram-se com uma frequência superior textos sobre a escola ou a solidariedade, por exemplo.

Essa escassez, aparentemente paradoxal, de textos sobre livros e leitura explica também a escassez de perguntas nas actividades que a tomam como tópico. $\mathrm{Na}$ verdade, é possível hipotetizar que a existência de textos ou referências textuais à leitura ou actividades com ela relacionadas pode constituir-se como um factor de abertura a interacções que impliquem alguma reflexão sobre essa prática sociocultural e, logo, aos seus valores pessoais e sociais. Assim, por exemplo, um texto sobre emigração é gerador de actividades que, de uma forma ou de outra, levam o aluno a posicionar-se relativamente a esse assunto, proporcionando, em 
consequência, situações nas quais se podem desenvolver, articular, reforçar e desafiar concepções e visões do mundo.

É, aliás, nesse sentido que se pode argumentar que o desenvolvimento da posição de leitor, numa dada conjuntura, é também feita do falar de leituras, isto é, a objectivar e instituir como objecto de análise as leituras representadas nos textos. Considere-se, a esse propósito, a actividade que ocorre a propósito de uma notícia sobre uma foca e de um texto de divulgação sobre os malefícios do ruído:

$[\ldots]$

3.1. que actuação deveriam ter as Câmaras e Secretarias de Estado do Ambiente para com as empresas que poluem o ambiente?

3.2. A operação de captura e transporte da foca para a Cornualha custou cerca de 500 mil escudos. Achas que foi bem empregue o dinheiro?

3.3. Se mandasses, que medida tomarias para diminuir a poluição sonora? (Man. R, p. 177)

Pese embora a orientação argumentativa dessas interrogativas, o que aqui se pede ao aluno é, de facto, um posicionamento ideológico, um "investimento", face a decisões de natureza política "reais" ou imaginárias. Não deixará de ser por isso que tal tipo de actividade é apresentado em muitos livros práticos dos novos estudos sobre a literacia como actividades que promovem o papel de leitor crítico.

Porém, quando em presença de situações de leitura como, por exemplo, a que é relatada num texto de Alves Redol (Man. R, p. 93), e cuja leitura, tal como nos dois textos agora citados sobre a defesa do ambiente, termina com uma actividade em que os exercícios são de opinião, o posicionamento exigido não é do mesmo tipo:

4.1. O que é um analfabeto?

4.2. A quem compete eliminar o analfabetismo? Quais as causas dele?

4.3. Haverá analfabetismo no nosso país? Qual a sua percentagem?

4.4. Um analfabeto será uma pessoa livre? Justifica. (Man. R, p. 94)

No caso dos textos da "foca" e do "ruído", estávamos perante situações que os alunos têm de se investir, resolvendo situações sob a 
forma de role-playing, trata-se o assunto como uma questão pessoal e, por meio de dispositivos vários como o verbo de opinião, a atribuição ao aluno de um papel na decisão, a simulação da situação, enfraquecem-se as fronteiras entre o universo de referência e os destinatários - alunos / leitores. A propósito da leitura, o assunto é tratado num quadro de forte exterioridade aos sujeitos: sobre o analfabetismo pede-se uma definição e percentagens (conhecimento que os alunos certamente não possuirão); para assumir a responsabilidade na resolução do fenómeno invoca-se um "outro" por meio da variável quem; as causas parecem poder ser bem identificadas tal como as dos fenómenos da natureza; a solicitação de opinião é seguida, tal como qualquer saber declarativo em avaliação, pela forma mais forte de directividade, o imperativo justifica. As diferentes escolhas linguísticas tomadas num e noutro caso contribuem para que a defesa do ambiente surja, assim, como um problema dos alunos e para o qual eles podem contribuir com soluções. Diversa é a questão do analfabetismo.

Esse último caso é ainda exemplar ao nível das "actividades" incluídas na secção "análise de texto", que, nos manuais, acompanham os textos. O texto é sobre trabalhadores que querem aprender a ler, contra a vontade do capataz que reprova tal atitude, com os argumentos de que "Para terem ideias más já lhes chega a cabeça, quanto mais os papéis..." Em nenhuma pergunta se pede ao aluno um juízo sobre essa posição; solicitase, no entanto, que o aluno se anule enquanto sujeito para, encarnando a pessoa do capataz, ajuizar sobre um dos factos textuais: a aprendizagem realizada por um dos trabalhadores: "No ponto de vista do capataz, terá sido positiva ou negativa a aprendizagem de Francisco Teimas? Justifica." (Man. R, p. 94)

Verifique-se que os alunos terão de dizer que a aprendizagem de Francisco Teimas foi negativa, repetindo os mesmos argumentos do tal capataz. Ao contrário, a posição do engenheiro que, às escondidas, ensina os trabalhadores a ler, em pergunta nenhuma é seleccionada para discussão. Não ocorrendo nenhuma actividade que suscite uma efectiva apropriação do texto pelos alunos, a posição de leitor que se lhes atribui é fortemente marcada pela exterioridade: o problema do analfabetismo é apenas um problema do texto, não é de ninguém em particular.

Sabemos que os textos dão origem a actividades para além da de leitura: escrita, oralidade, que sempre elegem o tópico do texto como elemento estruturador. A propósito de um conto de José Rodrigues Miguéis 
- "Arroz do céu”, por exemplo, encontramos actividades sobre problemas de emigração:

Em Portugal existem muitas comunidades emigrantes: caboverdianas, indianas, moçambicanas, angolanas, etc.

A - Averigua na tua zona se existem comunidades de emigrantes...

B - Organiza um debate na aula sobre este assunto. (Man. C, p. 29)

Ao nível da sala de aula, quanto mais textos sobre um determinado assunto, mais oportunidades ocorrerão para dele se falar. Mesmo da própria leitura, como poderia acontecer a partir do exemplo seguinte que ocorre após um texto intitulado "Eu sou o livro" e cujo último parágrafo também se transcreve:

Não me maltrates nem me desprezes. Muito sofri para trazer-te a sabedoria dos antigos, as lições da experiência, a expressão dos prosadores e poetas que enriquecem a tua língua materna e fizeram meigo e suave o teu idioma. Ama-me e lê-me: eu sou o teu livro. (Man. I, p. 36)

Aqui, actividade que se solicita é simplesmente: "Aprecia o último parágrafo do texto numa composição cuidada." (idem)

Sendo esse um dos raros exemplos em que, na totalidade dos manuais analisados, se solicita uma reflexão sobre a leitura e os livros, não deixa de ser significativa a forma como se posiciona o aluno perante o excerto que, já de si, é também esclarecedor quanto à representação de livro que veicula. Perante um valor quase supremo que impõe aos leitores uma atitude de total submissão e veneração, aos alunos é solicitada uma atitude duplamente distintiva: uma "apreciação" - comentário com uma orientação positiva, num texto de características formais elevadas. No exemplo transcrito, quer no texto da antologia quer na solicitação, ambos marcados pela expressão de ordem, a relação entre textos e alunos está fortemente hierarquizada, e os sentidos de leitura solicitados estão, à partida, fortemente condicionados pelas características dos textos verbais em que têm de ocorrer. $\mathrm{O}$ foco dessa tarefa pode, por isso, ser visto mais como visando a reprodução de uma determinada atitude do que, propriamente, a compreensão do texto. Compreender esse texto significaria, por exemplo, perceber como funcionam ali os mecanismos que colocam em jogo determinados modos de significação. A tarefa solicitada, nesse caso, funciona como um dispositivo que apenas reforça a natureza da representação de livro já plasmada no texto. 
São actividades como essa e, sobretudo, em lugares como esse, que contribuem para ajustar o posicionamento dos sujeitos à comunidade de prática em que estão a ser inseridos e aí reforçar ou excluir identidades.

\section{Mundos de Leitura}

A inserção dos sujeitos numa comunidade de leitores passa, entre outras coisas, pela criação de contextos onde a leitura desempenhe funções sociais diversas e valorizadas pelos sujeitos que nela se envolvem.

Esse princípio parece ter vindo a ser, em contexto português, progressivamente incorporado pela produção literária para a juventude, no qual as jovens personagens aparecem envolvidas em eventos de literacia ou que pelo menos a supõem para a realização das mais diversas tarefas. Seria então de esperar que à selecção dos textos narrativos dos manuais pudesse igualmente presidir aquele critério - aliás como tem vindo a acontecer em alguma produção televisiva para jovens.

No sentido de testar essa hipótese, foram analisados todos os textos narrativos do conjunto atrás identificado, recorrendo-se para isso às categorias "sujeitos", "tipo de vento", "objectos", "finalidades", "lugares" e "tempo" de leitura.

Os dados quantitativos obtidos, relativos às três primeiras categorias, apresentaram-se com a seguinte frequência:

\begin{tabular}{|c|c|c|c|c|c|c|}
\hline \multicolumn{7}{|c|}{ Algumas dimensões das práticas de leitura } \\
\hline \multicolumn{2}{|c|}{ Sujeitos } & \multicolumn{2}{c|}{ Tipo de Evento ${ }^{13}$} & \multicolumn{3}{c|}{ Objectos } \\
\hline Jovem & Adulto & Privado & Público & Literário & $\begin{array}{l}\text { Não } \\
\text { literário }\end{array}$ & $\begin{array}{l}\text { Não } \\
\text { especificado }\end{array}$ \\
\hline 65 & 36 & 68 & 33 & 38 & 35 & 28 \\
\hline
\end{tabular}

Por recurso exclusivo aos valores da categoria "sujeitos" que, nos mundos textuais, aparecem como actores principais ou secundários de

13 Entende-se por eventos de leitura "públicos" as situações dialógicas, em contextos de interacção familiar, escolar, laboral, etc., nas quais os sujeitos falam sobre as suas leituras. Por eventos de leitura "privados", tomam-se as situações em que as personagens ou o narrador fazem referência a momentos de leitura vividos individualmente. 
eventos de literacia, não é possível dizer com segurança que a leitura seja representada como uma tarefa específica dos jovens, apesar da superioridade de ocorrências. Mesmo assim, por relação a situações em que os adultos estão envolvidos em práticas de literacia, como neste excerto de O primo Basilio:

Tinham dado onze horas no "cuco" da sala de jantar. Jorge fechou o volume de Luís Figuier que estivera folheando devagar, estirado na velha Voltaire de marroquim escuro, espreguiçou-se, bocejou [...]. [Luísa] Ficou sentada à mesa a ler o diário de Notícias... (Man. N, p. 106),

aquelas em que os leitores são jovens, como no exemplo seguinte, tendem a aproximar-se do dobro: "A minha colega de carteira é uma aluna exemplar. Gosta de ler poesia. Já conseguiu levar-me a ler alguns poemas.” (Man. E, p. 105)

Uma análise desta categoria “sujeitos", em função da variável género, permitiu observar que, quando se trata de jovens, a distribuição é equitativa. Pelo contrário, entre os adultos, são mais os homens que aparecem envolvidos em práticas de literacia. Em família, por exemplo, é o pai que aparece ora a ler o jornal ora a ler histórias aos filhos: "[...] o meu pai e eu, quando estávamos juntos nunca nos aborrecíamos [...] Se estávamos fartos de ler...” (Man. R, p. 62)

Com base na oposição entre "eventos de leitura" "públicos" e "privados", classificaram-se as 101 passagens das narrativas. Os valores resultantes, constantes do quadro atrás, dão conta de uma maior frequência de situações em que os sujeitos se encontram a ler (ou estudar) sozinhos ou a recordar as suas leituras de recreação:

Depois, à noite, aconchegada mais a gola do casaco de trinta Invernos, ia meter-se em casa, a sós com os seus livros, arranjados não se sabia onde. Lia, fumava o seu cachimbo e esperava... (Man. F, p. 80);

Toda a noite virada aos livros (Man. R, p. 84);

Na minha juventude antes de ter saído de casa de meus pais disposto a viajar eu conhecia já o rebentar do mar das páginas dos livros que já tinha lido. (Man. P, p. 126)

A análise das situações públicas segundo o estatuto das personagens intervenientes (jovem-jovem; adulto-jovem; adulto-adulto) permitiu concluir da prevalência (quase o dobro) de eventos em que interacção é 
entre um jovem e um adulto. Essa diferença de estatuto, que aponta para diferentes graus de controlo entre os sujeitos, traduz ambientes pedagógicos, mesmo quando o adulto não é um professor em sentido formal. De facto, os actos verbais produzidos por estes adultos podem ser vistos como actos pedagógicos exibindo graus distintos de directividade:

Vê lá se estudas, para ver se és alguém [discussão entre mãe e filha] (Man. N, p. 36);

Mandaram-me reler o Diário de Anne Frank... (Man. D, p. 87).

Quando lemos devemos mostrar-nos simultaneamente disponíveis para receber e preparados para discutir... [conselho de um professor aos alunos] (Man. A, p. 13).

Igual valor parecem ter as situações interactivas envolvendo adultos, as quais tendem, também, a reproduzir essas mesmas situações pedagógicas; apesar disso, localizam-se, neste grupo, quase todos os casos em que as relações dos sujeitos são de igualdade:

Desculpe-me, caro amigo: será possível que leia ao mesmo tempo O futuro da Argentina, Espelho da sociedade..., O fio escarlate? Ri-me e admiti que $O$ fio escarlate me cativara mais a atenção. (Man. B, p. 82)

Enquanto tópico de conversa informal, a leitura entre pares não parece ser uma característica desses manuais, ainda o sendo menos quando se trata de situações entre jovens e adultos. A leitura de que nessas situações se fala é quase sempre uma leitura de tipo escolar ou alvo de alguma forma de prescrição.

Com a categoria "objectos" visava-se aceder, por um lado, aos intratextos - textos de que se fala nas antologias - e, por outro lado, aos textos que, fazendo parte de uma memória individual do autor da história, são também parte da memória colectiva, no sentido em que aquela é "feita também daquilo que nos é contado, do que se lê...” (JÚDICE, 1997, p. 91).

Como se viu no quadro atrás, não parece haver diferenciação entre a leitura de textos literários e de não literários - macrocategorias aqui adoptadas. A recorrência, entre os primeiros, de obras e autores do cânone literário juvenil - Defoe; Verne; Salgari; Carroll - é, com certeza, um indicador da razão que esteve na base da selecção do texto em que são referidos. Em função desses títulos e autores de que falam as personagens, reforça-se a hipótese de os textos antologiados não serem imunes à intenção pedagógica de organização da experiência pessoal. Contudo, tal 
facto não encontra qualquer tradução em actividades subsequentes. $\mathrm{Na}$ verdade, uma análise das actividades propostas para o trabalho com os textos que continham aquelas referências permitiu concluir que há um apagamento total de informação sobre esses autores, personagens e obras.

Nos textos em que a leitura referida é de outro âmbito que não a de literatura, parece estar subjacente uma intenção de natureza curricular, uma vez que, embora esteja pontualmente representado um leque variado de objectos (cartas, jornais, relatórios, livros técnicos, manuais de instruções), os dicionários e as enciclopédias são os dois objectos mais frequentemente referidos nas práticas de literacia das jovens personagens dos textos narrativos desses manuais:

Tinha trabalho a fazer na biblioteca... quando cheguei $[\ldots]$ senteime e peguei no dicionário. (Man. Q, p. 97);

Esta da potestade tinha eu lido nos Lusíadas. E só me convenci de que não era palavrão no dia em que fui ao dicionário e lá vi... (Man. M, p. 33);

Os dicionários e os livros da turma estão ali à nossa disposição, na aula de Português. (Man. E, p. 105)

Pertencem esses excertos a narrativas produzidas para um público jovem e se, por um lado, podem ter sido escolhidos para o manual por terem como personagens também jovens com quem, genericamente, os alunos se podem identificar, o facto de serem seleccionadas essas e não outras passagens pode ser visto como mais um caso de exemplaridade de comportamento adequado. Essa hipótese vê-se reforçada quando, no discurso sobre os textos, designadamente o configurado nos enquadradores, podemos encontrar juízos sobre a maior ou menor adequação dos comportamentos das personagens, do tipo: "Gineto rouba, escorraça [...] não está disposto a cumprir as ordens do pai. Enfim, não é um garoto exemplar.” (Man. K, p. 71).

Pesem embora as referências que permitem distinguir o tipo de texto lido, o mais comum nestes intratextos são situações em que havendo referência ao acto de ler, não há, contudo, qualquer especificação do objecto de leitura. Se entendermos que esta indeterminação é, pela ênfase que se coloca na actividade, uma forma de a valorizar em detrimento do texto; se considerarmos ainda que, particularmente neste contexto escolar, os textos privilegiados são os de poesia ou ficção, os valores atrás obtidos pela leitura de textos de literatura saem aumentados. Assim, uma situação 
como a seguinte: "A Susana foi a ler todo o caminho..." (Man. Q, p. 96) não será, ao nível da recepção, muito distinta daquelas em que se refere o género, o título ou o autor: "Voltei então a me empolgar [...] pelas aventuras de Robinson Crusoé." (Man. N, p. 77)

$\mathrm{Na}$ imagem mental construída pelo leitor, o que a Susana vai a ler é, sem grande margem de erro, um texto de literatura. A reforçar essa interpretação do valor obtido pelos excertos em que não se especifica o objecto, concorrem também as representações dos próprios alunos, cujos textos sobre a leitura são usados em alguns desses manuais: "[...] por isso é importante ler [...] Por entre comédia, aventura, mistério, há sempre um livro que nos aguarda." (Man. D, p. 77)

Entre os alunos, ler equivale, também, a ler determinados textos. Directamente relacionados com os "objectos" estão os "objectivos" da leitura. A sua identificação obrigou a movimentos de inferência, na medida em que raramente se encontram explicitamente afirmadas as razões que estão por detrás dos eventos de leitura em que se encontram ou são referidos pelas personagens. Num dos casos atrás citados, por exemplo, nada no excerto diz para que é que o jovem foi mandado reler o Diário de Anne Frank.

No entanto, como a maior parte dos exemplos convocados permitiu já dar conta, as motivações individuais ou sociais que organizam tais eventos são, fundamentalmente, a recreação cuja mais-valia é a informação que dela se obtém, como os seguintes exemplos colocam em evidência:

- E tu que fazias?

- Lia um livro estupendo

- O tal?

- Sim. [...] Fala de índios, de esquimós (Man. H, p. 37);

Tenho óculos graduados, tenho a mania dos livros [...] Este q.b. quer dizer quanto baste e aprendi no livro de receitas da minha mãe, o que prova que em toda a parte se pode aprender. (Man. D, p. 69-70)

Leitura para recreação e aprendizagem andam nesses contextos sempre intimamente associadas e são as facetas sistematicamente privilegiadas nestes mundos textuais: a leitura dá informação; uma informação que é sempre prazer. Essa é, sem dúvida, uma representação que nada acrescenta à representação vulgar, limitando-se os manuais a reproduzi-la. Para esse fim, chegam a ser actualizados dispositivos pelos 
quais se instaura uma discriminação social que coloca os que não são de leituras entre o grupo dos brutos: "O Governo, que era homem de leituras, explicou àqueles brutos que...” (Man. F, p. 175)

Com efeito, as práticas sociais da leitura e os valores para elas sempre apontados - a fruição, o lazer e a consequente aprendizagem - são a expressão de uma visão particular e redutora da leitura. Ao restringir-se a tais finalidades e valores, ao excluírem-se outras possibilidades, excluemse de caminho os sujeitos que não as reconhecem como suas e do seu grupo. Dessa forma, os leitores desses manuais são colocados numa posição em que têm de renunciar aos seus valores e práticas ou numa outra em que as têm de avaliar como negativas e não adequadas naquele domínio de literacia concreto.

Não se podendo ver as finalidades da leitura dissociadas dos "lugares" onde se lê, o movimento analítico seguinte visou identificar esses locais. Embora se tivesse notado alguma diversidade de textos não-literários, estes, no entanto, não encontram tradução em contextos outros que não a escola e a casa. E se as referências aos textos de literatura estão, aqui, privilegiadamente associados à casa, para as bibliotecas, por exemplo, está reservada, em exclusividade, a leitura de dicionários e enciclopédias.

À excepção de situações que fazem envolver os professores e em que estes, no âmbito do seu trabalho, lêem para a classe, apenas ocorre um caso de leitura em contexto de trabalho. Nos textos analisados não se encontram sujeitos a ler nos seus locais de actividade quotidiana, a não ser que esta tenha lugar na escola. Escola ainda, mesmo quando se trata de adultos e onde estes desempenham papéis de professor e alunos, como no já referido texto de Alves Redol.

Todos os dados recolhidos parecem conjugar-se para a conclusão de que o cenário de referência dessas leituras é sempre a escola, mesmo que não se esteja orientado por um questionário ou por um exercício para o dia seguinte:

A Rita encontrou o Abílio e, quase sem darem por isso, começaram a falar de aulas.

- Já leste o conto Abyssum Abyssus?

- Esse ainda não! O que eu li foi o Abissus Abyssum

- E a obra de leitura recreativa para este período? Qual é que vais ler? (Man. J, p. 20) 
Mesmo que aconteça fora dela, a leitura realizada nesses contextos é na generalidade das situações uma leitura em função da escola. É ainda um ler para a escola no sentido em que anda associada aos objectivos que a esta são cometidos: ensinar. Nesse sentido, a hipótese inicial sobre estarmos, nos textos desses manuais, perante contextos em que ler é, sobretudo, uma actividade que diz respeito aos jovens, vê-se com mais este contributo reforçada porque, a diversos níveis, é pontuada.

Com a mesma orientação dessa especialização da leitura na população juvenil, vão também as referências ao "tempo" em que esses eventos de leitura acontecem. $\mathrm{Na}$ procura de respostas para perguntas como: é a leitura algo que se faz ocasionalmente? quando lêem os adultos?, verificou-se que os textos apresentam as personagens jovens a falar das suas leituras em curso, o que já se viu poder ser entendido como uma estratégia para promover a identificação mais imediata e directa entre o leitor/aluno e os textos, assim se potenciando envolvimento e interesse. Atentando nas formas verbais e nos seus valores aspectuais, damos conta de como as referências às leituras dos jovens nos situam ao nível dos valores durativos, os quais descrevem um processo em curso, uma prática frequente e com certa duração no tempo:

A minha irmã passa o tempo a mudar de roupa, a ocupar o telefone e a ler livros. (Man. N, p. 96);

E agora desde que leio Sócrates e a biografia de John Lennon, estou em crise de identidade. (Man. D, p. 87)

As personagens adultas, pelo contrário, falam sempre das suas actividades de leitura enquanto jovens e como prática que lhes era grata e produtiva na juventude: "Ele compreendia tudo, aliás tinham-lhe ensinado na escola e no liceu e aprendera nos livros...” (Man. I, p. 26).

Nos textos desses manuais, os adultos já não lêem nem parecem ter de ler. Para essas personagens adultas, os livros e os textos em geral são objectos associados à juventude, aos bons velhos tempos. A leitura é um facto da memória; a literatura, um objecto da infância. "Eu sozinho menino... lia a história de Robinson Crusoé...” (Man. N, p. 30)

Essa perspectiva de leitura como actividade predominantemente juvenil não parece poder ser vista como neutra e fruto de um acaso. Se, num certo sentido, pode funcionar como factor de atracção ou, como os autores dos manuais invocam para justificar a selecção dos textos, de adequação, noutro sentido, ela não pode ser desligada de uma concepção adulta sobre a educação do jovem e o lugar da leitura nela. Reproduzindo- 
se, assim, de certa maneira, o que Vieira diz sobre a leitura de livros: "Também à força de ler livros se aprende a doutrina que estes ensinam. Forma-se o gosto, nutre-se a alma com bons pensamentos..." (Man. I, p. 216).

Em tudo até agora visto prevalece uma concepção de que quem deve ler é a juventude, a qual, por isso, encontra os seus limites no período relativo à escolaridade. Se pela análise se desenhou um contexto pouco permeável ao comentário sobre a natureza dos textos lidos, criando-se um vazio do qual sai valorizado o acto de ler independentemente do que se lê, o mesmo não se verifica quando se trata de modos de ler. Estando, num grande número de casos, implícita a leitura silenciosa, o que parece ser significativo é a frequência da referência à leitura em voz alta. Assim, à única ocorrência onde se refere a leitura em silêncio: "Liam juntos ou um para o outro ou mesmo silenciosamente" (Man. H, p. 39), contrapõemse, entre muitos, casos como:

Lia com tanta inteligência e graça, que o Sr. José Fortunato confessava que muitas vezes, ouvindo-a, entendia coisas, em que debalde tentara penetrar... (Man. Q, p. 188);

Lia com o mesmo sentimento com que há dias, na aula, declamara os primeiros versos dos Lusíadas. (Man. M, p. 24);

O Gabriel leu e muito bem parte de $A$ árvore que cantava. (Man. B, p. 118).

No reconhecimento de que a leitura em voz alta é uma modalidade quase tipicamente escolar, não pode deixar de ter significado esta insistência: a leitura que "vale" nesta prática de literacia é aquela cujas características se aproximam das da escola; os leitores competentes são os que a sabem fazer.

Tal como com os valores apontados para a leitura, também essa valorização de uma das suas modalidades pode criar condições para o afastamento e para a resistência. Ler em voz alta é uma capacidade distintiva à qual anda associado o desenvolvimento da competência de leitura, embora não seja a única modalidade nem sequer encontre justificação em todos os domínios de prática. Escamotear esse facto é participar numa visão restrita e restritiva da literacia.

Todas as características identificadas, desde a especialização da leitura na população juvenil à sua íntima associação com os objectivos e actividades escolares, conjugam-se para permitir ver nos textos das 
antologias "exemplos de um determinado mundo de leitura". Mundo, no entanto, de grande trivialidade, na medida em que aos lugares comuns, à representação convencionada da leitura (que se esgota na própria leitura escolar) nada mais se acrescenta. Por tudo isso, pode concluir-se que a modalidade de leitura, apesar do objecto literário que a congrega, é uma actividade fundamentalmente eferente.

\section{O PRAZER PRESCRITO DA LEITURA}

Como se disse antes, para além dos textos narrativos foram igualmente analisados os 59 textos poéticos e enquadradores presentes nas actividades sobre os textos, do tipo dos seguintes exemplos:

Folhear um livro é espreitar para dentro de uma caixinha sem chave (Man. K, p. 68);

Abrir um livro/é ler as páginas inteiras/[...] (Man. A, p. 12);

Se entretanto [...] poisamos o nosso amigo livro... (Man. R, p. 61).

Se nos textos narrativos, só de forma mediada, se acede aos constructos configuradores das representações da leitura, nestes "expressivos", bem assim como nos enquadradores, a modalidade de expressão adoptada tende a constituir os poemas, os versos soltos, os pensamentos, os provérbios, os depoimentos e as declarações como fórmulas abertas e transparentes dos valores que se atribui à literacia, aqui, particularmente à leitura.

Procurados, então, complementos (adjectivos, frases relativas, etc.) e especificadores (sob a forma de expressões qualitativas) que, de alguma maneira, caracterizassem os nomes "livro" (ou variantes como "texto"), "leitura" ou também "ler", concluiu-se pela sua quase total ausência.

Apesar da ausência de modificadores, tanto o "livro" como a "leitura" não deixam de ter atribuídas propriedades específicas. A este nível, a estratégia adoptada para caracterizar os eventos e objectos de leitura é recorrentemente o recurso a formas de predicação próprias de enunciados definitórios: Abrir um livro é...Folhear um livro é... Ler é... Os livros são...

A partir dessa estrutura de definição, e porque o recurso ao verbo "ser" pode aqui ser visto como a expressão de "propriedades permanentes", é possível uma interpretação "gnómica" dos valores aspectuais expressos nesses enunciados. O mesmo é dizer que "aos estados 
de coisas descritos é atribuído o estatuto de verdades atemporais e eternas" (MATEUS et al., 1989, p. 93). Esse valor é extensível a enunciados em que, pelo recurso ao tempo verbal do presente simples, se exprime uma propriedade não limitada temporalmente, susceptível, portanto, de ser interpretada como veiculando o mesmo valor gnómico, próprio das "verdades científicas", dos dogmas:

A leitura educa o gosto... (Man. G, p. 117);

A Poesia abre para as palavras... (Man. M, p. 100);

O livro sabe/tudo o que vai pelo mundo/ [...] (Man. M, p. 162);

A leitura faz o poeta (Man. B, p. 214);

Ler é fazer amigos (Man. L, p. 10);

A leitura é uma chama que nunca se apaga, que ilumina mesmo depois de terminada... (Man. R, p. 6);

Ler dá-nos imaginação sem limites (Man. D, p. 77);

Ler é uma forma de viajar no tempo (Man D, p. 221);

Ler rima com prazer. Ler é sempre um prazer (Man. M, p. 228).

Também esses textos e esses enquadradores são dispositivos de constituição de uma determinada posição de leitor. Essa constituição ocorre quando, pelas definições e pelas metáforas usadas emergem, por um lado, os tipos de leituras que um leitor realiza (aparentemente a narrativa e algumas vezes a poesia ou esta como lugar de informação) e, por outro lado, quando se define a atitude relativamente aos textos e à sua leitura. A reificação da prática de leitura que ocorre na posição de "sujeito" sintáctico e a natureza dos verbos usados (educar, saber, contar) colocam o leitor em posição subalterna e dependente de uma acção que sobre ele se exerce externamente. Ler é viajar, é ver de fora, é receber. a leitura dános...; o leitor é um recipiente.

Mas um dado leitor é ainda constituído quando é convocado e tornado alvo de orientações para a acção segundo normas relativas ao processo de leitura válido, num quadro marcado por uma hierarquização forte e pela directividade: "Lê um livro, menino,/porque o teu livro sabe/ tudo o que.......] (Man. M, p. 162); "[...] propomos-te que leias com prazer." (Man. E, p. 6) 
A localização do leitor num lugar fora da leitura é particularmente ilustrado, nesse último exemplo, quando o próprio prazer de ler é entendido como um modo de leitura. O prazer como alvo de prescrição, muito recorrente nesses manuais, atinge o seu grau máximo ao serem assertadas no domínio da "certeza" as emoções a obter e obtidas pela leitura: "Lendo, gozaste o prazer de aventura!” (Man. B, p. 74).

Acresce que, como nesse caso, a localização no passado permitirá ainda interpretar assunções desse tipo como muito carregadas por valores do domínio do obrigatório. Aliás, os enunciados em que, de forma mais ou menos circunscrita, o leitor é convocado parecem servir todos para a orientação quanto às atitudes com que se deve levar a cabo a leitura. A sua natureza de orientação torna-os particularmente permeáveis à expressão da prescrição. $\mathrm{Na}$ verdade, é neles que se realizam algumas expressões que aparecem modalizadas por meio quer de verbos que obrigam a interpretações deônticas quer por formas que avaliam negativa ou positivamente algumas dessas atitudes:

Quando lemos [...] devemos mostrar-nos disponíveis (Man. A, p. 13);

A leitura por prazer deve existir [...] mas como certamente não queres reduzir o teu prazer de ler (Man. H, p. 18);

Nada existe de mais desastroso do que abordar um livro sem simpatia. (Man. A, p. 13);

É importante criar e alimentar o gosto pela leitura recreativa, isto é, a leitura por prazer (Man. L, p. 38).

Os modos de ler configurados nesses textos pertencem sempre a um domínio inquestionável, pouco polémico, caracterizável quase como inefável, transcendente. Dada essa característica que se alarga às propriedades, às finalidades, em suma, a todos os argumentos que dão sentido, aqui, às práticas de leitura, essas orientações não pretenderão, naturalmente, funcionar como verdadeiras orientações, isto é, como guia para práticas efectivas. Não parece ser essa a função das representações emergentes dos manuais; mais do que normas para a acção, a forma com que se revestem transformam-nas em normas para a aceitação. Nesse quadro, a própria leitura deixa de aparecer como uma prática para a qual podem ser definidas regras cuja aquisição é transformadora dos sujeitos, para emergir como um valor que não se discute. 


\section{A literacia da escola como prática de aceitação e MANUTENÇÃo do SILÊNCIO ("SEM BATER O PÉ")}

Analisando as representações da leitura nos manuais, designadamente nos textos narrativos, poéticos e enquadradores, vimos um quadro geral marcado pela escassez de textos sobre a leitura ou que para ela remetam; quadro que, à partida, a coloca num lugar secundário da escala de valores privilegiados pelos manuais, na sua acção de constituição e regulação dos universos legítimos, numa comunidade de que ele é um dos principais porta-vozes. O quadro esboçado permitiu, mesmo assim, dar conta dos contornos de representações de leitura e verificar como diversos mecanismos actuam para lhes dar coesão, nessa medida fortalecendo o seu poder conformador do tipo de posicionamento dos sujeitos nas suas relações com o mundo configurado.

Naturalizando uma atitude eferente perante a leitura dos textos, constitui-se também um certo leitor. Este é um sujeito passivo e reprodutor, cujo estatuto de leitor dura enquanto dura a escola: as respostas que se lhe atribuem (e permitem) privilegiam a aquisição e evocação de saberes literais e a reprodução oral dos textos.

Nos textos antologiados, pela repetição e redundância de contextos, aparentemente o único dispositivo do manual para fazer relacionar alunos e contextos de leitura, as relações intertextuais que permitem vão apenas no sentido da confirmação e concordância. Por outro lado, o recurso exclusivo a esquemas convencionais tende tão só a ser gerador de uma aceitação acrítica desses mesmos esquemas. Não oferecendo hipóteses alternativas, caracterizações pluridimensionais nem conteúdos ou mesmo estruturas problemáticas, os textos sobre a leitura tendem apenas a reforçar crenças. Crenças que se impõem como verdades inquestionáveis e que se visam inculcar por meio de mecanismos discursivos de vária ordem: definições, discurso directivo, recurso a estereótipos.

Nas diferentes situações, a forma de relação entre sujeitos e textos caracteriza-se por uma clara marcação de papéis entre os receptores e os autores. Em todos os níveis de análise, essas duas categorias são rigidamente definidas, hierarquizando-se, por meio de metáforas gastas, os papéis de texto e leitor: o livro sabe tudo; o leitor aprende com ele. Um aprender que é sempre praz̧er sem condiçoes.

Nessa prática consensual que podemos dizer de sobrecodificação, os contornos da actividade de leitura convencionada são definidos pelas 
vozes que mutuamente se sancionam, pelo que a atitude é ainda a da aceitação e do silenciamento das múltiplas vozes que, na sala de aula, estão em confronto. Por isso, também relativamente à leitura, no quadro alargado do "letramento escolar", "a manutenção do silêncio - em nome da correcção - e a manutenção do silêncio - em nome da globalização e da hegemonia de um pensamento único - são dois lados de uma mesma moeda" (GERALDI, 2006, p. 14).

\section{Referências Bibliográficas}

BARTON, D.; HAMILTON, M. Local literacies: reading and writing in one community. London: Routledge, 1998.

BARTON, D.; HAMILTON, M.; IVANIC, R. (Ed.). Situated literacies: reading and writing in context. London: Routledge, 2000.

BERNSTEIN, B. The structuring of pedagogic discourse. In Class, codes and control. London: Routledge, 1990. v. IV.

CASTANHEIRA, M. L. et al. Interaccional Ethnography: an approach to studying the social construction of literate practices. Linguistics and Education, Stamford, spetial edition, 11 (4), p. 353-400, 2001.

CASTRO, R. V. Para a análise do discurso pedagógico: constituição e transmissão da gramática escolar. Braga: CIED, 1995.

CASTRO, R. V.; DIONÍSIO, M. L. A produção de sentido(s) na leitura escolar: dispositivos pedagógicos e estratégias discursivas no "trabalho interpretativo". In: FELTES, H. P. M. (Org.) Produção de sentido: estudos transdisciplinares. São Paulo: Annablume; Porto Alegre: Nova Prova; Caxias do Sul: EDUCS, 2003. p. 313-339.

COMBER, B.; CORMACK, P. Looking beyond "Skills" and "Processes": Literacy as social and cultural practices in classrooms. Reading, Oxford, p. 22-29, November 1997.

DENDRINOS, B. Prática ideológica em textos pedagógicos no ensino de Inglês como língua estrangeira. In: PEDRO, E. R. (Org.) Análise crítica do discurso: aspectos teóricos, metodológicos e analíticos. Lisboa: Caminho, 1997.

DIONÍSIO DE SOUSA, M. L. A interpretação de textos na aula de Português: aspectos da interacção verbal. Porto: ASA, 1993.

DIONÍSIO, M. L. A construção escolar de comunidades de leitores. Coimbra: Almedina, 2000.

DOMINGOS, A. M. et al. A teoria de Bernstein em sociologia da educação. Lisboa: Fundação Calouste Gulbenkian, 1986. 
GEE, J. P. Social linguistics and literacies: ideology in discourses. 2. ed. London: Taylor \& Francis, 1999.

GERALDI, J. W. A presença do texto na sala de aula. In: LARA, G. M. P. (Org.) Lingua(gem), texto, discurso: entre a reflexão e a prática. Belo Horizonte: FALE/ UFMG; Rio de Janeiro: Lucerna, 2006. p. 13-29.

HAROCHE, C.; HENRY, P.; PÊCHEUX, M. La Sémantique et la Coupure saussurienne: langue, langage, discours. Langages, Paris, n. 24, p. 93-106, 1971.

JÚDICE, N. A representação na construção ficcional. Revista da Faculdade de Ciências Sociais e Humanas, Lisboa, n. 10, p. 91-96, 1997.

LUKE, A. How to make literacy policy differently: generational change, professionalisation, and literate futures. In: JOINT NATIONAL AATE/ALEA CONFERENCE, Hobart, Tasmânia, July 13, 2001. (Manuscrito cedido pelo autor).

MATEUS, M. H. et al. Gramática da língua portuguesa. 2. ed. rev. e aum. Lisboa: Caminho, 1989.

PASSOS, M. Letramento literário na escola: um estudo de práticas de leitura de literatura na formação da "comunidade de leitores". Tese (Doutorado em Educação) - Faculdade de Educação, Universidade Federal de Minas Gerais, Belo Horizonte, 2006.

STREET, B. Literacy in theory and practice. Cambridge: Cambridge University Press, 1984.

\section{Bibliografia Passiva}

AMSELLEM, A. et al. LP 7: Língua Portuguesa, $7^{\circ}$ ano. Porto: Areal Editores, 1992. [Man. H]

ARAÚJO, H. et al. Lingua Portuguesa 7. Lisboa: Texto Editora, 1993. [Man. G]

BAPTISTA, V. S.; PINTO, E. C. Outros signos: Português, $7^{\circ}$ ano. Lisboa: Lisboa Editora, 1992. [Man. K]

CARRIÇO, L. et al. Nos caminhos do texto: Língua Portuguesa, $7^{\circ}$ ano. Porto: Porto Editora, 1992. [Man. I]

COSTA, F.; CASTRO, R. Viagens em Português 7. Porto: Porto Editora, 1992. [Man. R]

DEPARTAMENTO DE INVESTIGAÇÕES EDUCATIVAS, Leituras 7. Lisboa: Constância Editores, 1992. [Man. C]

DEPARTAMENTO DE INVESTIGAÇÕES EDUCATIVAS, Lingua Portuguesa 7. Lisboa: Constância Editores, 1992. [Man. F]

GOMES, Á.; BAPTISTA, F. P. Sinfonia da palavra 7. Porto: ASA, 1992. [Man. P] GOMES, H. M. et al. A aventura da palavra. Lisboa: Didáctica Editora, 1992. [Man. A] 
GUERRA, J. A. F.; VIEIRA, J. A. S. Aula viva: Língua Portuguesa, $7^{\circ}$ ano. Porto: Porto Editora, 1992. [Man. B]

MAGALHÃES, G.; CARDOSO, L. Recolha de textos e caderno de leitura orientada. Lisboa: Raiz Editora, 1992. [Man. O]

MELLO, C. et al. Travessia: Língua Portuguesa, 7². Lisboa: Ed. O Livro, 1991. [Man. Q]

NINA, I. L. P.; DELGADO, I. T. L. Palavras andantes: Português, $7^{\circ}$ ano. Lisboa: Presença, 1992. [Man. L]

PINTO, J. M. et al. Percursos: Língua Portuguesa, $7^{\circ}$ ano. Lisboa: Plátano Editora, 1992. [Man. N]

RAMOS, L. et al. M. Ler as palavras: Língua Portuguesa, $7^{\circ}$ ano. Lisboa: Texto Editora, 1992. [Man. D]

ROCHA, R. Ler, escrever, owvir, falar: Língua Portuguesa, $7^{\circ}$ ano. Coimbra: Minerva, 1992. [Man. E]

SOARES, M. A. Palavras certas: Língua Portuguesa, $7^{\circ}$ ano. Lisboa: Texto Editora, 1992. [Man. M]

VERÍSSIMO et al. O gosto das palavras 7. Porto: Areal Editores, 1992. [Man. J]

Recebido em: 23/10/2006

Aprovado em: 15/11/2006 